\title{
Kompleksitas Rezim di Uni Eropa: Upaya Penanganan Pengungsi dan Pencari Suaka
}

\author{
Lunyka Adelina Pertiwi
}

\begin{abstract}
This paper discusses regime complexity in European Union regarding its efforts to handle the influx of refugees and asylum seekers. By using qualitative method, this paper explains to what extent of regime complexity in European Union and how Germany, as a superpower in European Union, parse the complexity. An analysing process applies concepts of regime complexity and strategic inconsistency. The paper concludes that German try to parse the regimes network in European Union which is very complex and overlapping through strategic inconsistency, namely changing and maximizing its goods and externalities, and individual situation, so European Union successfully reduce the influx of refugees and asylum seekers and implement burden-share.
\end{abstract}

\section{Keywords:}

refugees and asylum seekers; regime complexity; strategic inconsistency; goods and externalities; individual situation.

\begin{abstract}
Abstrak
Tulisan ini mendiskusikan kompleksitas rezim di Uni Eropa dalam upaya penanganan gelombang pengungsi dan pencari suaka. Menggunakan metode kualitatif, tulisan ini menjelaskan sejauh mana kompleksitas rezim serta bagaimana Jerman sebagai superpower di Uni Eropa mengurai kompleksitas tersebut. Proses analisanya mengaplikasikan konsep kompleksitas rezim dan strategic inconsistency. Tulisan ini menyimpulkan bahwa Jerman berupaya mengurai jaringan rezim di Uni Eropa yang sangat kompleks dan tumpang tindih melalui strategic inconsistency yaitu mengubah dan memaksimalkan goods and externalities dan individual situation yang dimilikinya sehingga Uni Eropa berhasil mengurangi lonjakan pengungsi dan pencari suaka sekaligus menerapkan burden-share.
\end{abstract}

\section{Kata kunci:}

pengungsi dan pencari suaka; kompleksitas rezim; strategic inconsistency; goods and externalities; individual situation.

\section{Pendahuluan}

Uni Eropa adalah organisasi regional yang berusaha memerhatikan semua aspek. Uni Eropa menjunjung tinggi prinsip kebebasan (freedom), keamanan (security) dan keadilan (justice) melalui kebebasan berpindah (freedom

\footnotetext{
- Alumni S2 Hubungan Internasional FISIPOL UGM. Email: lunyka.pertiwi@gmail.com
}

of movement) demi tercapainya integrasi, khususnya di bidang ekonomi. Sebagai wilayah yang dijuluki "benua yang menawarkan kedamaian dan kesempatan", Uni Eropa beserta anggotanya berada dalam lingkup rezim perlindungan pengungsi dan Hak Asasi Manusia PBB. Meskipun menandatangani Deklarasi Hak Asasi Manusia, Konvensi Geneva 1951 dan Protokol 1967, Uni Eropa 
kemudian menciptakan skema sendiri dalam mengatur prosedur suaka. Di sisi lain, rezim keamanan regional yang disepakati bersama sejak awal pembentukan Uni Eropa juga sangat penting bagi landasan keanggotaan organisasi ini.

Namun integritas dan kekompakan Uni Eropa dipertanyakan saat jumlah pengungsi dan pencari suaka terutama dari Timur Tengah dan Afrika yang tiba di Eropa melonjak tak terkendali tahun lalu. Pada kuartal pertamakedua tahun 2015 tercatat satu juta pengungsi dan pencari suaka baru (Council of Council, 2016). Jumlah ini mengalami peningkatan drastis dari tahun 2014, di mana pengungsi dan pencari suaka yang menuju Eropa tercatat 431.000 orang. Sejumlah 80 persen dari angka tersebut berasal dari Suriah, Irak dan Afganistan (Eurostat, 2016).

Fakta ini memicu beberapa negara Eropa Barat seperti Inggris dan Prancis serta Eropa Timur seperti Hungaria, Slovakia, Bulgaria, Rumania dan Ceko meningkatkan level penjagaan dan proteksi atau "to maintain and to protect" ${ }^{\prime \prime}$ perbatasan agar meredam bahkan mencegah masuknya pengungsi dan pencari suaka ke negara mereka yang melewati Turki. Sedangkan Austria tanpa berkeinginan menampung pengungsi dan pencari suaka terlebih dulu, justru seringkali membiarkan mereka melintas perbatasannya agar semuanya bisa menuju Jerman (The Guardian, 2015).

Italia dan Jerman menuduh telah absennya solidaritas negara-negara Uni Eropa terhadap permasalahan ini. Italia, negara persinggahan pertama bagi pencari suaka dan pengungsi

\footnotetext{
To maintain and to protect merupakan tindakan suatu negara untuk mempertahankan keamanan batas negara mereka dan melindunginya dari gelombang imigran ilegal termasuk kelompok pengungsi tanpa dokumen. To maintain and to protect ini diimplementasikan melalui proses cek dan kontrol yang dilakukan oleh polisi perbatasan negara tersebut di wilayah-wilayah yang berbatasan dengan negara lain. Wilayah-wilayah perbatasan ini biasanya menjadi pintu masuk utama bagi para imigran ilegal dan pengungsi tanpa dokumen (HM Government, 2014).
}

yang menempuh jalur laut, mengkritik Uni Eropa yang terkesan lepas tangan atau "at a distance". Ini dikarenakan minimnya bantuan finansial dan teknis dari Uni Eropa bagi Italia yang sudah kerepotan menampung pengungsi dan pencari suaka yang singgah sementara, ditambah berbagai insiden kecelakaan kapal pengangkut pengungsi dan pencari suaka yang tenggelam di sekitar wilayah perairannya (Tazzioli, 2015).

Kompetensi Uni Eropa pun dinilai kurang dalam mengantisipasi lonjakan jumlah pengungsi dan pencari suaka hingga menimbulkan ketegangan politik internal di antara negara-negara anggota. Kompleksitas rezim yang ada di Uni Eropa ternyata tak mampu menghasilkan kebijakan yang reaktif dan tepat.

Kompleksitas rezim yang dihadapi Uni Eropa meresahkan superpower di Uni Eropa yang juga negara tujuan favorit bagi pengungsi dan pencari suaka, Jerman (Cooper, 2016). Melalui open-door policy-nya ${ }^{2}$, Jerman hingga tahun 2015 sudah menerima $+1,1$ juta pengungsi dan pencari suaka, 476.649 diantaranya berasal dari Suriah atau dua kali lebih banyak dari jumlah di tahun 2014 (Aljazeera, 2016). Meskipun mengklaim tidak kekurangan sukarelawan dan dana tetapi pospos pengungsi di Jerman telah kewalahan dan kelebihan beban. Angka kriminalitas berupa kasus penyerangan oleh pengungsi terhadap warga lokal juga naik signifikan dan tentu akan membahayakan stabilitas keamanan domestik Jerman (Karnitsching, 2016). Oleh karena itu, Jerman berusaha mengurai kompleksitas rezim agar Uni Eropa menetapkan kebijakan yang mampu menyelesaikan persoalan yang berkaitan dengan lonjakan jumlah pengungsi dan pencari suaka.

\footnotetext{
2 Kebijakan suatu negara yang mengizinkan pengungsi, pencari suaka dan pekerja asing untuk melewati batas wilayahnya, menetap, bekerja serta menikmati perlindungan sosial dan hukum tanpa diskriminasi (Hanau, 2007, 47-48)
} 
Tulisan ini akan memfokuskan pada pembahasan mengenai kompleks jaringan rezim di Uni Eropa dalam upaya penanganan pengungsi dan pencari suaka. Selain itu, tulisan ini mencoba memberikan penjelasaan mengenai upaya Jerman membantu Uni Eropa dalam mengurai kompleksitas rezim dan menetapkan kebijakan penanganan pengungsi dan pencari suaka. Dua fokus pembahasan tersebut akan dijelaskan secara teoritis menggunakan konsep kompleksitas rezim yang akan menyertakan indikator kompleksitas rezim dan konsep strategic inconsistency. Strategic inconsistency dapat bersifat non-institutional bargaining ${ }^{3}$.

Tulisan ini menggunakan metode penelitian kualitatif. Penelitian kualitatif adalah jenis untuk memahami fenomena tertentu secara holistik yang digambarkan dan dijelaskan secara deskriptif (Moleong, 2007: 4-6). Adapun sumber untuk memperoleh data penelitian, penulis menggunakan teknik studi kepustakaan. Data-data penelitian ini diperoleh dari buku-buku akademik, artikel dan jurnal cetak maupun online, serta pernyataan resmi (tertulis) dari pejabat pemerintah, yang berkaitan dengan konsep kompleksitas rezim dan strategic insonsistency, gelombang pengungsi dan pencari suaka di Eropa, rezimrezim di Uni Eropa dan upaya Jerman dalam mengurai kompleksitas rezim tersebut.

\footnotetext{
3 Strategic inconcistency bertujuan untuk membentuk aturan tertentu yang bertentangan dengan suatu rezim. Strategic inconsistency dapat dilakukan melalui melalui pembentukan rezim atau institusi baru, memanfaatkan institusi yang sudah ada atau menerapkan cara unilateral tertentu. Sementara melihat pada penjelasan Oran Young, sebuah pendekatan institutional bargaining dalam konteks rezim bertujuan untuk membentuk sebuah institusi atau rezim baru. Selain itu kesepakatan dalam pendekatan institusional bargaining harus bersifat unanimity atau kebulatan suara sehingga tidak ada peran mayoritas, sehingga strategic inconsistency yang tidak dilakukan dengan proses pembuatan rezim atau institusi baru dapat dikatakan bahwa strategic inconsistency ini dilakukan dengan pendekatan noninstitutional bargaining.
}

\section{Konsep Kompleksitas Rezim dan Strategic Inconsistency}

Negara-negara merancang sebuah rezim dengan berlandaskan pada kepentingan mereka. Menurut S. Krasner, "rezim adalah satu set prinsip, norma, aturan dan prosedur pembuatan kebijakan baik yang bersifat implisit maupun eksplisit yang meliputi ekspetasi aktor-aktor yang terpusat dalam hubungan internasional" (Rothwell, 1996: 405). Salah satu contoh rezim adalah rezim internasional nonpoliferasi atau non-pengayaan senjata nuklir yang memiliki prinsip yaitu non-proliferasi, pembatasan senjata atau disarmament dan pemanfaatan teknologi nuklir secara damai (Miller, 2012: 5).

Suatu rezim dapat bersifat tidak statis. Apabila rezim diperkirakan kurang relevan dalam menyelesaikan suatu masalah atau mengakomodir aspek tertentu, maka kekurangan tersebut coba dilengkapi oleh penerapan sebuah rezim lain. Situasi ini yang dapat digolongkan kompleksitas rezim (Koehane \& Victor: 2010; Ross \& Bekkevold, 2016). Amandine Orsini (2013), mengatakan "rezim yang kompleks adalah jaringan antara dua atau tiga rezim atau lebih yang berhubungan dengan satu subjek yang sama, menunjukkan keanggotaan yang tumpang tindih, menghasilkan interaksi substantif, normatif dan operatif yang diakui sebagai masalah potensial, contohnya apakah rezim-rezim tersebut diatur secara efektif" (Sperling, 2014: 84). Sedangkan, menurut Alter and Meunier (2009), "kompleksitas rezim internasional merujuk pada kemunculan sekumpulan rezim internasional yang bersifat paralel dan sebagian tumpang tindih dengan hierarki tidak teratur" (Sperling, 2014: 84).

Terdapat enam indikator primer yang dapat dipergunakan untuk menganalisa kompleksitas rezim (Orsini, Morin \& Young, 2013: 29-31), yaitu: 
1. Keanggotaan tumpang tindih.

Hal ini bisa terjadi pada anggota organisasi regional biasanya juga bergabung dengan anggota rezim lain bahkan di luar wilayah regionalnya.

2. Divergensi elemen konstitutif

Elemen konstitutif yang dimaksud contohnya seperti norma, aturan dan prosedur yang dimiliki beberapa rezim. Akan tetapi elemen konstitutif tersebut memiliki divergensi signifikan. Apabila divergensi norma, aturan atau prosedur antara rezim rezim tersebut kecil rezim tersebut tidak dapat dikategorikan kompleks. Divergensi dapat dapat dilihat dari (poin-poin) konvensi atau perjanjian yang direvisi dan/atau disepakati antar negara.

3. Terdapat sekurang-kurangnya tiga elemen rezim.

Ini biasanya menjadi indikator kompleksitas rezim tunggal. Contohnya rezim hak asasi manusia yang meliputi elemen pencari suaka, hak pekerja, keamanan sosial, hukum, dan lain lain.

4. Memiliki satu ranah pembahasan.

Walaupun rezim-rezim tersebut berbeda sebetulnya mempunyai satu ranah isu yang sama.

5. Tidak adanya hierarki yang jelas dan tegas antar rezim.

Tumpang tindih rezim antara rezim-rezim tersebut disebabkan tidak adanya hierarki yang jelas dan tegas rezim mana yang mempunyai kekuasaan lebih besar jika dihadapkan untuk menyelesaikan suatu persoalan.

6. Adanya perbedaan perspesi antar negara anggota dalam memandang suatu masalah.

Kompleksitas rezim akan semakin bertambah apabila saat rezim-rezim tersebut akan digunakan untuk menyelesaikan masalah ternyata terjadi perbedaan persepsi dari negara-negara anggota mengenai masalah tersebut. Suatu atau beberapa rezim tidak dapat dikatakan kompleks jika anggotanya mempunyai satu pandangan yang sama terhadap suatu masalah.

Kompleksitas rezim dapat menimbulkan konsekuensi positif bahkan negatif. Meminjam istilah Tamar Gutner (2016), efek paling ekstrem adalah kompleksitas rezim sangat mungkin untuk tidak melahirkan outcome yang lebih baik. Kompleksitas rezim sanggup mengurangi efektivitas dari rezim itu sendiri dan turut membawa pengaruh negatif pada proses pembuatan keputusan dan strategi politik suatu negara. Efek negatif dari kompleksitas rezim disebabkan samarnya hierarki antara rezim-rezim tersebut, membuat aktor-aktor internasional, terutama negara seringkali menemui kesulitan dalam menunjuk rezim mana yang digunakan untuk menyelesaikan suatu isu internasional meskipun mereka telah meratifikasi rezim-rezim tersebut di lingkup domestik mereka.

Konsekuensi dari kompleksitas rezim tersebut dapat diselesaikan dengan strategic inconsistency. Strategi ini memungkinkan aktor negara menawarkan aturan yang kontradiktif agar menciptakan konflik atau pertentangan, melemahkan perjanjian lain dan mendesak adanya perubahan pemahaman atau adaptasi aktual dari poin-poin di rezim lainnya (Pollack dan Shaffer, 2009: 131). Anggapan bahwa strategi ini sering dijalankan oleh negara kuat sinkron dengan yang diutarakan Drezner (2009), “kompleksitas rezim justru dapat memperkuat posisi sebuah negara yang paling kuat"(Sperling, 2014: 87). Misi akhir strategic inconsistency adalah menjadi penentu atau focal point dalam proses rekonsiliasi dan tawar menawar serta mempengaruhi keputusan aktor lain (Raustiala \& Victor, 2004: 300).

Strategic inconsistency dapat dipraktekan melalui langkah memanfaatkan dorongan atau impetus seperti peristiwa penting yang terjadi saat itu di lingkup domestik, regional 
atau internasional. Dorongan itulah yang dikombinasikan dengan salah satu atau beberapa faktor dominan dari goods and externalities, individual situation dan institution (Aggarwal, 1998: 11).

Faktor goods umumnya berupa suatu komoditas atau sumber daya bersama seperti peraturan ataupun komitmen bersama. Goods ini dikombinasikan dengan externalities karakterisitik tertentu di dalam lingkungan eksternal negara tersebut, contohnya konflik, aliansi, kerja sama, sanksi ekonomi yang terjadi antar negara, dependensi atau kepanikan regional terhadap suatu aturan. Selanjutnya, faktor individual situation adalah posisi tawar atau kekuatan tertentu yang dimiliki suatu negara, seperti kapabilitas nasional (ekonomi, militer dan politik) dan belief atau kepercayaan para elite politik yang jika dimaksimalkan mampu mempengaruhi suatu rezim atau melemahkan lawan politiknya. Terakhir, faktor institusi (regional atau internasional), merupakan wadah di mana suatu negara berinteraksi dengan negara-negara lain (Aggarwal, 1998: 11).

Trik suatu negara dalam mengelola strategic inconsistency-nya adalah dengan mengoptimalkan salah satu atau beberapa dari tiga faktor diatas agar dapatmengkontradiksikan suatu rezim dengan isu, aksi atau aturan unilateral tertentu. Strategic inconsistency yang menggunakan atau mengkombinasikan goods and externalities dan individual situation biasanya tidak akan mengarah pada pembentukan dan/atau perubahan (aturan) institusi (noninstitutional bargaining). Non-institutional bargaining memfokuskan pada proses tawar menawar yang tidak menargetkan pembentukan suatu insitusi baru atau mengubah struktur atau karakteristik utama institusi yang sudah ada. Sedangkan institutional bargaining adalah inversinya (Aggarwal, 1998; Nagel, 2000; Ostrom \&Dietz, 2002).

\section{Kompleksitas Rezim di Uni Eropa dalam Menghadapi Lonjakan Jumlah Pengungsi dan Pencari Suaka}

Uni Eropa sebenarnya bukanlah komunitas dan organisasi regional yang anti terhadap pengungsi dan pencari suaka. Sejak Perang Dunia II, banyak migran, pengungsi dan pencari suaka dari berbagai negara dan zona konflik telah bergabung menjadi masyarakat regional Uni Eropa. Sikap negara-negara Uni Eropa berubah saat jumlah pengungsi dan pencari suaka yang tiba di Eropa tahun 2015 melonjak drastis dan terkesan tidak terkendali. Mereka masuk dari berbagai penjuru khususnya jalur laut yang kemudian singgah di Italia dan Yunani, dan jalur darat, melintasi perbatasan Turki-Eropa.

Lonjakan jumlah pengungsi dan pencari suaka ini ternyata merupakan masalah krusial bagi Uni Eropa dan negara anggotanya. Diprediksi peningkatan tajam akan trus terjadi karena zona perang dan konflik di Afrika dan Timur Tengah semakin meluas dan belum terselesaikan. Terlebih lagi di benak para pengungsi dan pencari suaka, hidup di Eropa dirasa mampu menjamin masa depan mereka (Al-Jazeera, 2015)

Di tengah keharusan untuk meneguhkan upaya penanganan terhadap arus pengungsi dan pencari suaka, Uni Eropa justru terikat dalam jaringan rezim yang kompleks. Kompleksitas tersebut dilihat dari penjelasan beberapa poin berikut;

Pertama, Uni Eropa sendiri tidak mampu menampik tumpang tindih keangotaan. Semua negara Uni Eropa merupakan anggota PBB yang menandatangani Deklarasi Hak Asasi Manusia, Konvensi Geneva 1951 dan Protokol 1967 sehingga terikat pada rezim perlindungan HAM dan perlindungan pengungsi. Padahal dalam lingkup regionalnya, negara-negara tersebut terikat dengan beberapa rezim yaitu freedom of movement dan keamanan regional. 
Kedua, divergensi elemen konstitutif seperti aturan dan prosedur antar rezim terlihat cukup kentara. Tercantum dalam UNHCR: The Refugee Convention 1951 pasal 33, asas "non refoulement" yaitu melarang suatu negara untuk mengusir pengungsi ke negara asalnya di mana kehidupannya akan terancam" (UNHCR, 1992). Negara-negara Eropa juga telah meratifikasi Protokol 1967 yang merupakan penyempurnaan beberapa pasal di Konvensi Geneva mengenai definisi pengungsi. Asas non-refoulement sebetulnya diadopsi dalam treaty pembentukan Masyarakat Ekonomi Eropa Pasal 63 (1), “setiap negara anggota harus mengusung cara-cara penanganan pengungsi sesuai dengan prinsip-prinsip dalam Konvensi Geneva" (Grubbs, North \& World Law Group, 2003: 202). Selanjutnya, hak mencari suaka ${ }^{4}$ dijabarkan sebagai berikut, "setiap orang berhak untuk mencari dan mendapat suaka untuk menghindari tuntutan hukum" (Declarations of Human Rights, 1948, Article 14).

Sementara, Uni Eropa yang dibentuk dengan fondasi keragaman, terdapat pula freedom of movement ${ }^{5}$ yang bukan sekedar konsep tetapi sudah bertransformasi menjadi sebuah rezim. Dalam perkembangnya, freedom of movement lebih sering dikaitkan dengan free movement of people yang melarang adanya diskriminasi kewarganegaraan bagi setiap individu yang ingin bermigrasi, pindah dari satu negara anggota ke negara anggota Uni Eropa lain untuk tinggal dan bekerja. Demi mendukung freedom of movement, eliminasi "kontrol dan cek perbatasan" dikukuhkan

\footnotetext{
${ }^{4}$ Hak ini tidak bisa diberikan kepada orang-orang yang mendapat tuntutan hukum atas tuduhan kejahatan non-politik dan kejahatan yang bertentangan dengan tujuan dan prinsip-prinsip yang ditetapkan.

5 Freedom of movement sebetulnya meliputi empat konten yaitu free movement of goods, free movement of services, free movement of capitals, dan free movement of workers. Tetapi dalam perkembangannya freedom of movement lebih identik dengan free movement of people karena secara otomatis perpindahan manusia akan membawa setidaknya salah satu aspek dari modal, servis dan barang.
}

melalui Schengen (Area) Agreement ${ }^{6}$. Uni Eropa kemudian memperluas subjek free movement of people, yang mencakup pekerja, pelajar, pengungsi dan keluarganya dari negara lain yang berada dan tinggal di Eropa.

Di sisi lain, masalah lonjakan pengungsi dan pencari suaka memaksa hampir semua negara baik secara implisit dan eksplisit memperhatikan keamanan nasionalnya. Mayoritas negara Eropa tidak ingin banyaknya pendatang termasuk pengungsi dan pencari suaka karena ingin mencegah adanya ancaman bagi keamanan, kehidupan sosial dan ekonomi domestiknya. Mereka mengkhawatirkan banyaknya pendatang akan mengikis identitas lokal, kekuatan ekonomi dan keamanan dan kedamaian masyarakat asli secara dramatis. Hak yang merupakan bagian hak asasi ini dilindungi oleh rezim keamanan regional yang termaktub dalam Hukum Uni Eropa pasal 4 (2): “.....Uni Eropa harus menghargai fungsi esensial dari sebuah negara untuk melindungi integrasi wilayahnya dan mempertahankan peraturan dan hukum serta menjaga kepentingan nasionalnya. Secara khusus, keamanan nasional tetap merupakan tanggung jawab tunggal dari setiap negara anggota" (Peers, 2013: 54).

Ketiga, di satu rezim yang berkaitan dengan kasus ini, terdapat lebih dari tiga elemen. Contohnya, rezim HAM juga memuat aspek keamanan individu, migrasi, hukum, hak hidup, dan bahkan keamanan sosial dan ekonomi warga negara. ${ }^{7}$ Ini bisa dilihat dari

6 Pada awalnya Schengen Agreement hanya ditandatangani oleh Belgia, Jerman Barat, Luksemburg, Prancis dan Belanda dan baru menyepakati persoalan eliminasi kontrol perbatasan di wilayah kelima negara tersebut. Pada tahun 1990, diadakan Schengen Convention yang kemudian menyepakati adanya common- Schengen visa policy (kebijakan visa bersama) di antara kelima negara tersebut. Kini, Schengen Area sudah diberlakukan di hampir semua negara yang tergabung dalam Uni Eropa. Hanya Inggris dan Irlandia yang diberi hak istimewa untuk tidak menerapkan Schengen visa policy/ Schengen Area.

7 Situasi ini yang menyebabkan pula bahwa hak negara melindungi keamanan nasionalnya juga merupakan 
keseluruhan pasal-pasalnya (Declarations of Human Rights, 1948: Article 1-30; Shiman, 1999).

Keempat, rezim-rezim HAM, perlindungan pengungsi, freedom of movement dan keamanan regional jika ditelaah berada satu area atau irisan yang sama yaitu migrasi.

Kelima, telah timbul tumpang tindih antara rezim perlindungan pengungsi, rezim hak asasi manusia yang bersifat internasional dengan rezim freedom of movement dan rezim keamanan regional Eropa. Jika merujuk pada penjelasan Alter dan Meunier, tumpang tindih dikarenakan nihilnya hierarki yang jelas untuk menunjukan rezim mana yang mengandung power lebih kuat untuk menyelesaikan persoalan apalagi beberapa rezim juga mengandung banyak elemen-elemen dan poin-poin yang elusif (Alter\&Meunier, 2007: 1-28).

Keenam, hierarki yang tidak jelas antar rezim akhirnya menyebabkan negara-negara Uni Eropa mempunyai persepsi berbeda dalam mempertimbangkan fenomena lonjakan jumlah pengungsi dan pencari suaka di tahun 2015. Negara seperti Jerman masih mengutamakan nilai-nilai moral dengan membuka pintu bagi para pengungsi dan pencari suaka. Angela Merkel bahkan mengungkapkan bahwa negara negara Eropa tidak hanya harus membantu secara finansial melainkan juga harus bertanggung jawab secara kolektif untuk melindungi setiap individu yang hak-haknya terabaikan (Delcker, 2015). Kata lainnya, negara-negara Eropa hendaknya bersedia berbagi beban untuk menampung dan memberi ruang gerak bagi pengungsi dan pencari suaka yang ingin tinggal di Eropa (Delfs, Buergin \& De Beaupuy, 2015), tetapi negara-negara negara-negara Eropa Timur seperti Hungaria, Ceko, Rumania, Slovakia dan Austria melihat persoalan lonjakan jumlah pengungsi dan pencari suaka sebagai ancaman bagi keamanan domestik dan regional Eropa. Mereka berasumsi

hak asasi. bahwa pengungsi dan pencari suaka adalah kelompok minoritas yang tidak taat aturan dan membahayakan nilai-nilai tradisional bangsa dan keamanan Eropa. Hungaria menegaskan hanya akan membuka pintu bagi economic migrant yang diyakini dapat berkontribusi bagi pertumbuhan ekonomi. Menurut Perdana Menteri Hungaria, pengungsi dan pencari suaka adalah German problem karena Jerman memilih untuk menerima pengungsi sehingga negara-negara Eropa lain tidak berkewajiban mengikuti langkah Jerman (BBC, 2015).

Sementara Inggris menganggap bahwa menampung pengungsi dan pencari suaka dalam situasi di mana jumlah mereka tidak terkendali akan menyulitkan negara membedakan mereka dengan imigran ilegal. Bahkan Inggris tidak ingin keterbukaan negaranya pada pengungsi dan pencari suaka disalahgunakan oleh imigran ilegal tanpa skill yang hanya ingin hidup nyaman dengan jaminan sosial dari pemerintah Inggris. Bagi Inggris solusi terbaik untuk mengurangi jumlah pengungsi dan pencari suaka adalah stabilisasi keamanan di sejumlah negara Timur Tengah dan Afrika. Italia dan Yunani juga merasa sudah sangat terbebani dengan adanya Common European Asylum System $(\mathrm{CEAS})^{8}$ (Lehne, 2016) apalagi implementasi Global Approach to Migration and Mobility $(\mathrm{GAMM})^{9}$ juga stagnan. Maka, pertentangan

\footnotetext{
8 Dalam CEAS, terdapat Dublin Regulation yang menjelaskan secara detail poin-poin yang harus dipertimbangkan suatu negara dalam memproses aplikasi suaka, seperti latar belakang keluarga (apakah ada sanak saudara yang tinggal di salah satu negara Uni Eropa), kepemilikan visa atau izin tinggal di MEE dan sejauh mana aktivitas para aplikan memasuki Eropa (regular atau iregular). Dan tugas pemrosesan ini diserahkan pada negara pertama yang disinggahi para pengungsi seperti Italia dan Yunani (European Commission Fact Sheet, 2014).

${ }^{9}$ Tujuan GAMM adalah mendorong arus migrasi yang legal dan terorganisir, mengantisipasi dan melawan gerakan migrasi yang tidak beraturan (irregular), mengeleminasi perdagangan manusia, memaksimalkan pengaruh positif dari imigrasi dan mobilitas bagi pembangunan, dan mempromosikan proteksi internasional dan meningkatkan dimensi
} 


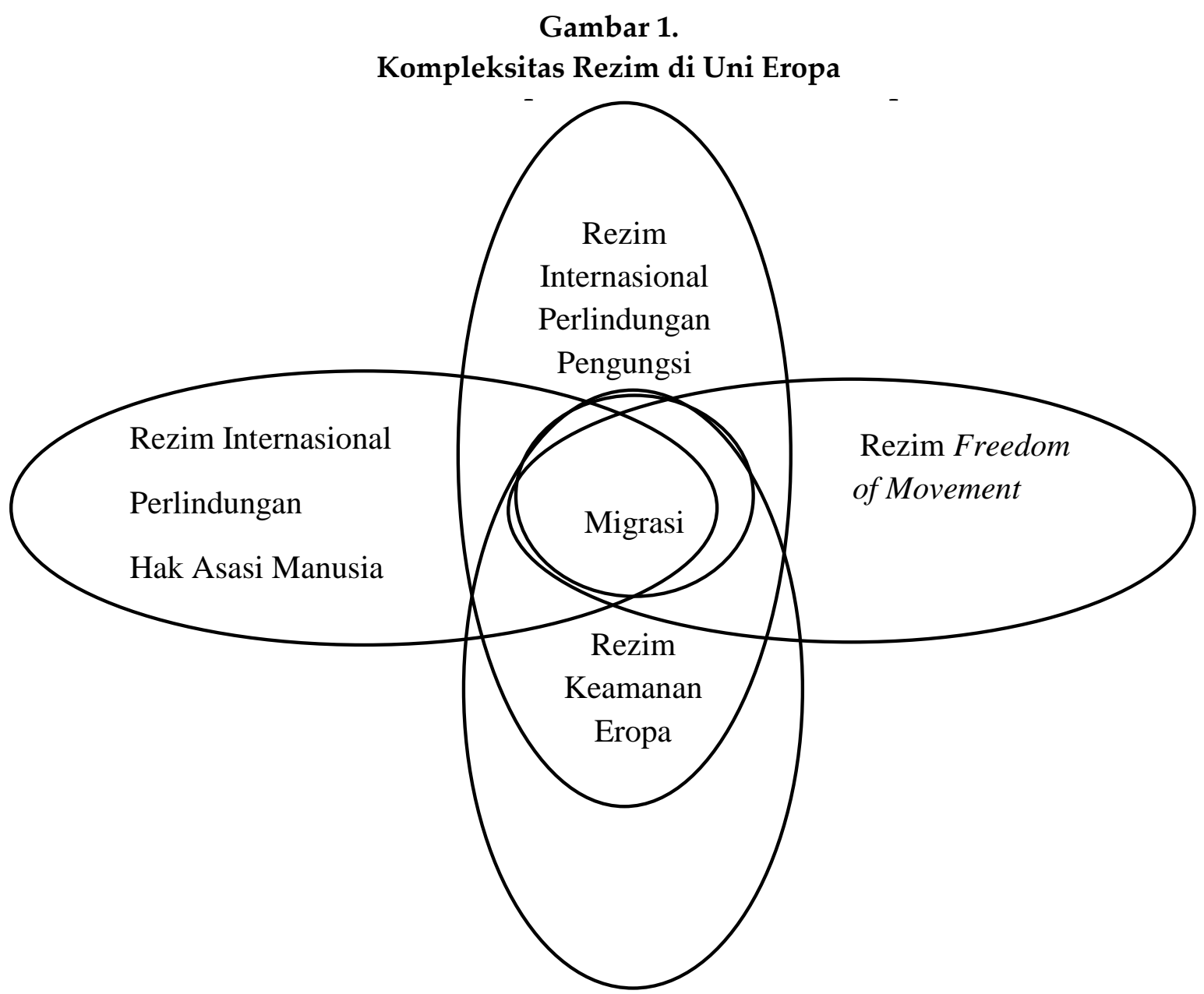

Sumber: Dikembangkan dari Plathner, 2013

cara pandang ini telah menggambarkan adanya konflik kepentingan antar negara anggota Uni Eropa. Alhasil, kompleksitas rezim yang bersifat tumpang tindih tersebut otomatis membingungkan Uni Eropa dalam menentukan rezim manakah yang paling layak bagi upaya penanganan gelombang pengungsi dan pencari suaka.

dari pencari suaka (European Commission, 2016). GAMM ini menekanakan pada proses negosiasi antara dengan negara-negara Afrika Utara agar bekerja sama dengan Uni Eropa dalam mencegah arus migrasi ilegal menggunakan kapal. Afrika Utara memang menjadi titik keberangkatan alternatif bagi kapal yang mengangkut pengungsi, pencari suaka dan ilegal migran yang berasal dari Afrika maupun Timur Tengah. Titik berlabuh mereka adalah Italia dan Yunani sebelum mereka meneruskan perjalanan ke negara-negara Eropa Barat dan Utara.
Di satu sisi, Uni Eropa sebagai bagian dari komunitas global yang terikat oleh rezim perlindungan HAM dan pengungsi tidak boleh mengabaikan nasib pengungsi dan pencari suaka yang membutuhkan perlindungan dan pertolongan di wilayahnya. Di satu sisi, Uni Eropa harus menghargai hak negara anggotanya untuk menjaga keamanan dan stabilitas nasionalnya dari efek negatif gelombang pengungsi dan pencari suaka. Kebingungan Uni Eropa semakin bertambah sebab alasan menjaga keamanan dan stabilitas nasional dapat digunakan oleh negara anggota tertentu untuk melakukan tindakan yang tidak manusiawi, seperti mengusir pengungsi dan pencari suaka atau membiarkan mereka hidup terlunta-lunta. Tindakan negara tersebut juga dapat mengancam keberlangsungan rezim 
kebebasan berpindah atau freedom of movement setiap individu (Independent, 2015; Sputnik News, 2015).

\section{Strategic Inconsistency Jerman dalam Mengatasi Kompleksitas Rezim di Uni Eropa}

Kompleksitas rezim yang mewarnai Uni Eropa ternyata menyulitkan Uni Eropa dalam menghasilkan kebijakan yang tepat. Apalagi terdapat pertentangan antara Inggris, Spanyol, Austria, dan mayoritas negara-negara Eropa Timur seperti Hungaria, Rumania, Bulgaria, Slovakia, Ceko melawan Jerman yang menuntut solidaritas negara-negara Uni Eropa.

Kondisi di atas berperan sebagai dorongan bagi strategic inconsistency Jerman. Jerman memahami bahwa solidaritas seharusnya menjadi public goods yang dapat mendorong pencapaian kebijakan bersama demi penyelesaian masalah yang sedang dihadapi Uni Eropa. Di lingkungan eskternal atau externalities Jerman, mayoritas negaranegara Uni Eropa menolak usulan Jerman karena mereka sedang memfokuskan diri pada pertumbuhan ekonomi nasional paska krisis 2008 melalui keberadaan Schengen Area. Sementara, individual situation Jerman yang menjunjung kebijakan open door policy bagi pengungsi dan pencari suaka justru menjadi celah bagi banyak negara Eropa Timur "menyalahkan" Jerman yang dinilai telah terjebak dalam moral imperialisme ${ }^{10}$ nya sendiri (Deutsche Welle, 2015; BBC, 2015). Maka stategic inconsistency yang digunakan Jerman adalah mengubah aspek public goods yang mulanya berupa isu solidaritas yang dikombinasikan sekaligus dikontradiksikan Jerman dengan isu Schengen Area. Jerman menghembuskan isu bahwa Schengen Area

\footnotetext{
${ }^{10}$ Moral imperialisme merupakan sebuah standar tinggi suatu negara dalam bersikap ramah dan berbelas kasihan terhadap kelompok manusia yang sedang menderita, di mana standar ini sebetulnya berusaha disebarkan ke negara lain
}

lebih baik berakhir dan Jerman juga tidak bisa menjamin keberlangsungan keanggotaannya dalam skema Schengen jika common policy mengenai pengungsi dan pencari suaka, berupa burden-share tidak segera tercapai dan terealisasi (The Telegraph, 2016).

Burden-share yang dimaksud Jerman merujuk pada konsep burden-share yang dikeluarkan pada Konvensi tentang Pengungsi tahun $1951^{11}$. Burden-share menekankan perlunya solidaritas dan kerjasama internasional antar negara dalam memberikan suaka dan menampung pengungsi sehingga bukan hanya negara-negara tertentu yang menanggung beban tersebut. Jerman menginginkan implementasi burden-share terhadap pengungsi dan pencari suaka yang ada di pos penampungan di Italia dan yang masuk melewati Turki (Boswell, 2003).

Jerman terus mengkonstruksikan isu Schengen Area yaitu mengindikasikan adanya implementasi kerjasama mini-Schengen ${ }^{12}$. Strategi ini ditujukan untuk mengubah exsternalities di sekitar Jerman dari dependensi semua negara terhadap Schengen Area menjadi kekhawatiran terhadap koalisi terbatas Mini-Schengen. Mini Schengen ini berupa penyempitan area pemberlakukan free-Scehengen passport yang hanya melibatkan Jerman, Belanda, Prancis, Belgia dan Luksemburg. Jerman berusaha memunculkan kekhawatiran Uni Eropa dan negara-negara Eropa Timur yang harus menerima konsekuensi berupa penurunan angka pertumbuhan ekonomi apabila miniSchengen benar-benar dilaksanakan (Lehne, 2016). Startegi yang berlawanan dengan rezim

\footnotetext{
${ }^{11}$ Lebih lanjut, burden share mengedepankan dua jenis aksi yaitu bantuan finansial dan pemindahan atau resttlement. Bantuan finannsial akan diberikan kepada negara-negara berkembang agar mereka dapat memperhatikan dan melindungi hak hak pengungsi yang ada di negara mereka. Bantuan resttlement berarti negara bersedia mengakomodir proses perpindahan dan menampung pengungsi dan pencari suaka yang lari dari zona konflik.

${ }^{12}$ Mini Schengen awalnya merupakan ide Belanda yang telah disampaikan secara internal dan bilateral kepada Jerman sekitar Oktober 2015
} 
freedom of movement ini juga diharapkan dapat mendorong negara-negara Eropa Timur dapat memikirkan kembali usul burden-share.

Selanjutnya, Jerman tidak lupa memaksimalkan individual situation berupa kekuatan politik-ekonomi dan tidak lagi berfokus pada open door-policy-nya agar dapat me-lobby beberapa pihak dan memberikan tekanan pada Uni Eropa dan negara-negara anggota lain. Jerman menjadi perantara bagi Uni Eropa dan Turki dalam skema perjanjian untuk menangani gelombang pengungsi dan pencari suaka. Jerman mengajukan usul bahwa pengungsi dan pencari suaka baru yang tiba di Yunani atau Italia akan dikirim ke Turki sebelum diperbolehkan masuk Eropa. Turki dipilih karena negara ini diyakini adalah negara (dunia) ketiga yang relatif aman menampung pengungsi dan pencari suaka. Turki dianggap mampu menopang Italia dan Yunani yang sudah kewalahan berperan sebagai garda terdepan untuk mengecek dan memproses kelengkapan dokumen para pengungsi dan pencari suaka, terutama yang menempuh perjalanan laut.

Kebijakan Jerman dalam mendukung proses pemindahan pengungsi dan pencari suaka dari Italia dan Yunani ke Turki dinilai berseberangan dengan asas non-refoulement yang terdapat dalam rezim perlindungan pengungsi. Selain itu, perjanjian ini memperlihatkan inkonsistensi Jerman terhadap rezim hak asasi manusia sebab Jerman seakan tidak memperdulikan keamanan dan kondisi kesehatan jangka panjang para pengungsi dan pencari suaka yang harus dikirim kembali ke Turki setelah menempuh perjalanan jauh melalui jalur laut. Namun di mata Jerman, perjanjian dengan Turki membantu menghilangkan kesan Eropa diserbu eksodus "berbahaya" pengungsi dan pencari suaka sehingga diharapkan negara-negara yang awalnya menolak keberadaan pengungsi dan pencari suaka mengubah kebijakannya (Akel, 2016; Presstv, 2016).
Selanjutnya, Jerman meminta bantuan pasukan koalisi NATO untuk ikut mengawasi proses pemindahan pengungsi dan pencari suaka yang dikirim dari Italia dan Yunani kembali ke Turki melalui jalur laut Aegea. Strategi ini sangat kontroversial sebab Jerman menggunakan political power sebagai negara besar untuk melibatkan NATO. Kebijakan ini di mata banyak organisasi kemanusiaan ditakutkan sebagai bentuk militerisasi dan tindakan represif terhadap pengungsi dan pencari suaka dan bertentangan dengan rezim hak asasi manusia. Tetapi Jerman berdalih keterlibatan NATO hanya memberi bantuan tambahan bagi Frontex untuk mencegah aksi penyelundupan manusia yang berkedok sebagai migran, pengungsi atau pencari suaka, sekaligus untuk mengatur arus pengungsi dan pencari suaka yang sebenarnya. Kebijakan ini diyakini mampu menjaga keamanan regional bagi Uni Eropa dan negara-negara anggota (Akel, 2016).

Jerman juga telah memberi tekanan bagi Uni Eropa dan negara-negara anggota lain agar meningkatkan solidaritasnya dalam masalah pengungsi dan pencari suaka. Contohnya, Jerman meminta polisi Italia untuk memperketat pengecekan dokumen bagi siapapun yang melewati perbatasan Jerman-Italia. Jerman kemudian juga menutup perbatasannya selama beberapa minggu dengan Austria dan menunda sementara rute kereta Jerman-Austria bagian Selatan. Sejak akhir 2015 Jerman bahkan secara bertahap mulai menerapkan "kontrol dan cek" melalui cara pemeriksaan identitas bagi penduduk yang akan melewati perbatasan Jerman dengan Austria. Jerman mengisyaratkan kebijakannya ini dapat berlangsung hingga dua tahun jika Austria tidak menunjukkan komitmen pada nilai kemanusian (The Telegraph, 2016). "Ancaman" Jerman ini berarti antipoda rezim freedom of movement, namun sebetulnya bertujuan untuk mendukung rezim HAM.

Outcome dari strategic inconsistency Jerman adalah Uni Eropa lebih mudah 
menyusun draft solusi yang mengatur alur penerimaan pengungsi dan pencari suaka dengan menyertakan platform burden share dan perjanjian Uni Eropa-Turki. Beberapa poin pokok perjanjian Uni Eropa-Turki adalah:

1. Menjadikan Turki sebagai negara yang menampung para pengungsi dan pencari suaka sebelum mereka dinyatakan legal masuk ke Eropa

2. Semua pengungsi dan pencari suaka yang tiba di Yunani dan perairan ItaliaYunani (setelah tanggal penandatanganan perjanjian, 20 Maret 2016) akan dikirim ke Turki agar didata secara resmi dan mencegah adanya imigran ilegal yang masuk dengan menyamar sebagai pengungsi serta mencegah potensi ancaman atau teroris sebelum mereka masuk ke Eropa

3. Penerapan sistem one-in, one-out untuk menentukan jumlah pengungsi dan pencari suaka yang disetujui oleh Uni Eropa. Artinya setiap ada satu pengungsi atau pencari suaka baru yang dikirim dari Yunani atau Italia maka Uni Eropa akan menyetujui satu orang pengungsi atau pencari suaka yang sudah sejak lama ditampung oleh Turki (The Guardian, 2016)

4. Uni Eropa memberikan 3.000.000.000 EUR per dua tahun kepada Turki agar dapat menyediakan makanan, tempat tinggal sementara, dan pendidikan bagi pengungsi dan pencari suaka disana

5. Distribusi pengungsi dan pencari suaka baik dari Turki maupun Italia dan Yunani ke Uni Eropa akan ditetapkan dengan skema kuota dan hanya diberlakukan pada negara-negara sudah menyatakan sukerela menampung mereka (European Council of the European Union, 2016).

Uni Eropa memang sempat mengalami ketegangan dalam negosiasi dengan Turki sebab Turki menginginkan jumlah bantuan 3.000.000.000 EUR diberikan setiap tahun disertai dengan syarat lain yaitu pembahasan kembali mengenai prospek keanggotaan Uni Eropa bagi Turki dan pemberiaan bebas visa bagi setiap penduduk Turki yang akan masuk ke Eropa (Global News, 2016). Tetapi paska beberapa pertemuan antara Turki dan Jerman yang mewakili Uni Eropa, akhirnya Uni Eropa menyetujui semua detail persyaratan yang diajukan Turki (New York Times, 2016).

Lima poin pokok perjanjian Uni EropaTurki tersebut kemudian disetujui Jerman, Prancis, Swedia, Finlandia, Belgia, Luksemburg, Belanda, Yunani, bahkan Austria, Ceko, Slovenia dan Lithuania yang disebut sebagai coallition of willing. Khusus untuk poin kelima ${ }^{13}$ merupakan poin yang harus dilaksanakan oleh negara-negara yang telah menyatakan setuju. Apabila terdapat negara yang melanggar poin tersebut, maka akan Uni Eropa akan menerapkan denda sebesar 250.000 EUR. Meskipun begitu, Uni Eropa mengindikasikan bahwa denda tersebut akan segera berlaku pula bagi negara-negara di luar coallition of willing yang sama sekali enggan menunjukkan solidaritas dalam penanganan pengungsi dan pencari suaka (EU Observer, 2015).

Startegic inconsistency Jerman yaitu mengubah dan memaksimalkan goods and externalities dan individual situation-nya, memang melemahkan beberapa norma rezim yang dianut Uni Eropa. Tetapi jalan tersebut secara signifikan berefek positif pada penurunan jumlah pengungsi dan pencari suaka baru yang memasuki Eropa melalui jalur laut Mediterania dan Aegean, yaitu dari $+100.000 /$ Januarimid Maret 2016 menjadi $+15.000 /$ AprilJuni 2016 (EU Observer, 2016, Traub, 2016). Selain itu, strategic inconsistency Jerman turut mempengaruhi kebijakan Inggris (sebelum “Brexit") ${ }^{14}$ yang berjanji akan menerima 20.000

\footnotetext{
${ }^{13}$ Pelaksanaan poin 1 hingga 4 dan poin 6 merupakan domain Uni Eropa.

${ }^{14}$ Tulisan ini memfokuskan pada periode sebelum terjadinya referendum Inggris yang menghasilkan "Brexit" ata keluarnya dari Uni Eropa. Dengan adanya "Brexit" otomatis kebijakan yang diambil saat
} 


\section{Gambar 2:}

\section{Alur Implementasi Strategic Inconsistency Jerman}

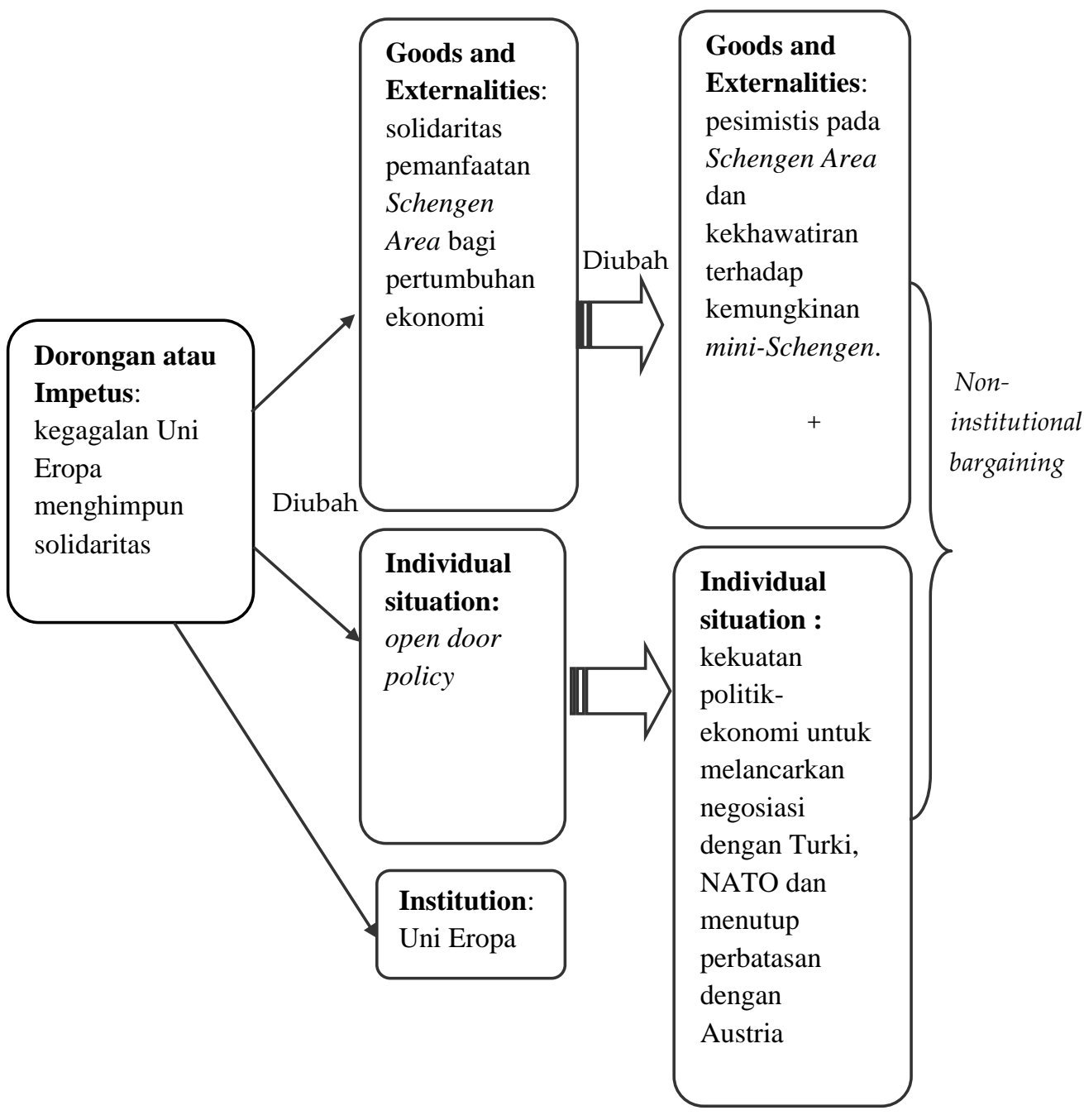

Outcomes:

-Kesepakatan

Uni Eropa-

Turki yang menyertakan aspek burden share

-Inggris

(sebelum

"Brexit"),

Austria, Ceko

dan Lithuania

setuju dengan

burden share

dan perjanjian

Uni

Eropa-Turki

- penurunan

jumlah

pengungsi dan pencari suaka

yang masuk

melalui jalur

laut
Sumber: diolah peneliti

pengungsi Suriah dari Turki secara bertahap (The Guardian, 2016).

Dari strategic inconsistency Jerman yang telah dijelaskan di atas, terdapat asumsi bahwa Jerman memutuskan tidak membentuk institusi baru maupun merombak lingkup

kepemimpinan David Cameron ini menjadi bersifat tentatif atau belum tentu akan diimplementasikan oleh Perdana Menteri baru yaitu Theresa May yang berasal dari Partai Konservatif. Terlebih lagi poin di tangan kepemimpinan baru ini, Inggris dikabarkan akan merombak aturan imigrasi pengungsi, pencari suaka dan pekerja asing dan berusaha lepas dari rezim kebebasan berpindah yang ditelah diterapkan Uni Eropa (Jill, 2016) atau prinsip fundamental Uni Eropa (noninstitutional bargaining), dengan alasan Jerman masih menghormati tiga pilar Uni Eropa ${ }^{15}$.

\section{Kesimpulan}

Tak terkendalinya jumlah pengungsi dan pencari suaka yang berdatangan ke daratan Eropa pada tahun 2015 menempatkan Uni Eropa dalam situasi genting. Organisasi regional ini dianggap gagal bereaksi cepat dalam menggalang solidaritas bersama

\footnotetext{
${ }^{15}$ European Community (pilar kesatu), common foreign and security policy (pilar kedua), dan cooperation in the fields of justice and home affairs (pilar ketiga).
} 
dan merancang kebijakan yang mampu menyelesaikan persoalan ini.

Situasi pelik yang dihadapi Uni Eropa disebabkan adanya kompleksitas rezim dalam kerangka Uni Eropa yang melibatkan rezim freedom of movement, rezim internasional mengenai perlindungan pengungsi, rezim hak asasi manusia, dan rezim keamanan Eropa. Hal ini tidak dapat dihindari kerena negaranegara anggota Uni Eropa memang merupakan bagian dari masyarakat global sekaligus terikat dengan rezim regional yang dibentuk Uni Eropa. Rezim-rezim tersebut memiliki elemenelemen konstitutif berupa norma, prosedur dan aturan yang cukup divergen. Terlebih lagi khusus di dalam rezim hak asasi manusia terdapat aspek keamanan individu, migrasi, hukum, hak hidup, dan bahkan keamanan sosial dan ekonomi warga negara. Meskipun mempunyai ranah atau irisan yang sama yaitu migrasi, tidak adanya hierarki yang jelas menyebabkan sulitnya menentukan rezim mana yang memiliki kekuatan hukum lebih kuat. Selain itu, perbedaan persepsi antar negara dalam memandang masalah lonjakan jumlah pengungsi dan pencari suaka semakin menambah kompleks jaringan rezim-rezim tersebut.

Situasi overlaping regime tersebut otomatis membingungkan Uni Eropa dalam menentukan rezim manakah yang paling layak bagi upaya penanganan gelombang pengungsi dan pencari suaka. Uni Eropa berada dalam dilema antara mempertahankan rezim perlindungan HAM dan pengungsi atau rezim keamanan regional yang melindung hak negara anggota untuk mempertahankan keamanan nasionalnya. Kebingungan Uni Eropa semakin bertambah karena alasan mempertahankan keamanan nasional dapat digunakan negara-negara tertentu untuk berupaya lepas tangan dari tanggung jawab moral membantu pengungsi dan pencari suaka. Selain itu, tindakan negara tersebut berarti mencederai prinsip kebebasan berpindah yang melekat pada setiap individu.
Absennya solidaritas bersama antar negara-negara Uni Eropa dalam menghadapi isu pengungsi dan pencari suaka menjadi dorongan bagi Jerman untuk menjalankan strategic inconsistency. Jerman jeli untuk mengkontrdiksikan isu solidaritas yang sebetulnya dapat menjadi goods, dengan isu Schengen Area. Jerman memperlihatkan sikap pesimis dengan Schengen Area. Selain itu, mengindikasikan implementasi mini-Schengen jika common policy mengenai pengungsi dan pencari suaka, berupa burden-sharing tidak segera terealisasi. Proses pengkonstruksian isu digunakan untuk mengubah externalities Jerman dari dependensi semua negara terhadap Schengen Area menjadi kekhawatiran terhadap penurunan pertumbuhan ekonomi.

Jerman kemudian mengedepankan individual situation berupa kekuatan politikekonominya dan tidak lagi berfokus pada open door policy. Menggunakan kekuatan politik-ekonomi tersebut, Jerman menjadi perantara bagi Uni Eropa dan Turki dalam skema perjanjian dalam menangani gelombang pengungsi dan pencari suaka. Jerman sepakat untuk memindahkan pengungsi dan pencari suaka yang mendarat di Italia dan Yunani ke Turki. Di sini terlihat inkonsistensi Jerman terhadap rezim hak asasi manusia.

Jerman juga memaksimalkan individual situation-nya untuk meminta bantuan pasukan koalisi NATO agar ikut mengawasi proses pemindahan pengungsi dan pencari suaka yang dikirim dari Italia dan Yunani ke Turki melalui jalur laut. Kebijakan ini dikategorikan sebagai bentuk militerisasi dan tindakan represif terhadap pengungsi dan pencari suaka, yang bertentangan dengan hak asasi. Selain itu, Jerman melakukan tindakan yang bertentangan dengan rezim freedom of movement melalui pemberlakukan cek dan kontrol di wilayah perbatasan dengan Austria dan Italia.

Outcome dari strategic inconsistency Jerman adalah Uni Eropa kemudian menyusun draft solusi yang intinya mengatur skema 
penerimaan pengungsi dan pencari suaka dengan menyertakan perjanjian Uni EropaTurki dan platform burden-share. Strategic incosnsistency Jerman secara tidak langsung berkontribusi pada penurunan jumlah pengungsi dan pencari suaka yang memasuki Eropa melalui jalur laut dan mendorong perubahan kebijakan Inggris (sebelum Brexit). Strategic inconsistency meskipun berlawanan dengan bebeberapa norma, aturan dan prosedur dari rezim-rezim yang diikuti oleh Uni Eropa, tetapi bersifat non-institutional bargaining di mana Jerman tidak mengarahkan pada pembentukan atau bergabung dengan institusi baru untuk melawan Uni Eropa.

\section{Daftar Pustaka}

Aggarwal, Vinod K. (1998). Institutional Designs for A Complex World: Bargaining, Linkages, and Nesting. New York: Cornell University Press.

Alter, Karen J. \& Meunier, Sophie. (2007). The Politics of International Regime Complexity. Buffett Centre for International and Comparative Studies Working Paper No. 07-003, 1-28.

Boswell, Christina. (2003). Burden-sharing in the New Age of Immigration. (Online) (http:// www.migrationpolicy.org/article/burdensharing-new-age-immigration, diakses 15 Juli 2016).

Cooper, Yvette. (2016). The Europan Refugee Crisis and Europe. (Online). (https://rusi.org/event/ refugee-crisis-europe, diakses 10 Juni 2016).

Delcker, Janosch. (2015). Merkel: Welcoming refugees 'right thing to $d^{\prime}$ '. (Online). (http:// www.politico.eu/article/merkel-welcomingrefugees-right-thing-to-do/, diakses $12 \mathrm{Mei}$ 2016). (http://belfercenter.ksg.harvard.edu/ publication/19880/regime_complex_for_ climate_change.html (Koehane and Victor)

Delfs, Arne, Buergin, Rainer. \& De Beaupuy, Francois. (2015). Merkel calls on EU to share burden of exploding refugee crisis. (Online). (http://www.stuff.co.nz/world/ europe/71582619/Merkel-calls-on-EU-to- share-burden-of-exploding-refugee-crisis, diakses 13 Mei 2016).

European Commision. (2014). European Comission Fact Sheet: A Common European Asylum System. Luxembourg: Publications Office of the European Union. . (2016). Global Approach to Migration and Mobility. (Online). (http:// ec.europa.eu/dgs/home-affairs/what-wedo/policies/international-affairs/globalapproach-to-migration/index_en.htm, diakses 11 April 2016).

European Council of the European Union. (2016). Refugee facility for Turkey: Member states agree on details of financing. (Online). (http://www.consilium.europa.eu/en/press/ press-releases/2016/02/03-refugee-facilityfor-turkey/, diakses 2 Mei 2016).

EuroStat. (2016). Asylum Statistics. (Online). (http://ec.europa.eu/eurostat/statisticsexplained/index.php/Asylum_statis, diakses 11 Mei 2016).

Grubbs, Shelby R., North, Peter M., World Law Group (2003). International Civil Procedure. Hague: Kluwer Law International.

Gutner, Tamar. (2016). International Organizations in World Politics. Washington DC: CQ Press.

Hanau, Peter. (2007). Employment of Foreign Workers and Social Equity: The German Experience. Ritsumeikan Law Review, No 24, 47-48.

HM Government. (2014). Review of the Balance of Competences between the United Kingdomand the European Union Asylum \& non-EU Migration. (Online). (http://www.nationalarchives.gov. uk/doc/open-government-licence/, diakses 12 Mei 2016).

Karnitschnig, Matthew. (2016). Angela Merkel's domestic security crisis: Cologne attacks 'changed everything' in German perceptions of migrants. (Online). (http://www.politico.eu/ article/angela-merkel-domestic-securitycrisis-cologne-refugees-debate-criminalsprotests/, diakses 12 Mei 2016). 
Keohane, Robert O. \& Victor, David G. Januari 2010. The Regime Complex for Climate Change. Harvard Project on Climate Agreements Discussion Paper Series. (Online). (http://belfercenter.ksg.harvard.edu/ publication/19880/regime_complex_for_ climate_change.html, diakses 22 Mei 2016).

Lehne, Stefan. (2016). How the Refugee Crisis Will Reshape the EU. (Online). (http:// carnegieeurope.eu/2016/02/04/how-refugeecrisis-will-reshape-eu/itj7, diakses 15 Juli 2016).

Miller, S. E. (2012). Nuclear Collisions: Discord, Reform $\&$ the Nuclear Nonproliferation Regime. Cambridge, Mass: American Academy of Arts and Sciences. (Online). (https:// www.amacad.org/multimedia/pdfs/ publications/researchpapersmonographs/ nonproliferation, diakses pada $25 \mathrm{Mei}$ 2016).

Moleong, Lexy J. (2007). Metodologi Penelitian Kualitatif. Bandung: Penerbit PT Remaja Rosdakarya Offset.

Nagel, Stuart. (2000). Handbook of Global Economic Policy. New York \& Basel: Marcel Dekker. Inc.

Orsini, A., Morin, J.F., \& Young, Oran. (2013). Regime Complexes: A Buzz, a Boom, or a Boost for Global Governance. Journal of Global Governance 19, 27-39.

Ostrom, Elinor \& Dietz, Thomas. (Eds). (2002). The Drama of the Commons. Washington DC: National Academies Press.

Peers, Steve. (2013). EU Justice and Home Affairs Law. Oxford: Oxford University Press.

Plathner, Christine. (2013). EU immigration and asylum policy from the perspective of regime complexity. Lund University: Department of Political Science (Online). STVM23, Spring. (Online). (http://lup.lub.lu.se, diakses 12 Mei 2016)

Pollack, Mark A \& Shaffer, Gregory C. (2009). When Cooperation Fails: The International Law and Politics of Genetically Modified Foods. Oxford: Oxford University Press.
Raustiala, Karen \& Victor, D. (2004). The Regime Complex for Plant Genetic Resources. International Organization 58, Spring. 277-309.

Rothwell, Donald. (1996). The Polar Regions and the Development of International Law. Cambridge: Cambridge University Press.

Ross, Robert R, \& Bekkevold, Jo Inge. (2016). China in the Era of Xi Jinping: Domestic and Foreign Policy Challenges. Washington DC: Georgetown University Press

Rutter, Jill. (2016). What Will Happen to U.K Immigrants after Brexit. (Online). (http:// www.new sweek.com/what-will-nowhappen-immigrants-after-brexit-480389, diakses 15 Juli 2016).

Shiman, David A. (1999). Economic and Social Justice: A Human Right's Perspective. (Online). (http:// www.umn.edu/humanrt, diakses 15 Juli 2016).

Sperling, James. (2014). Handbook of Governance and Security. Cheltenham \& Northampton: Edwar Elgar Publishing.

Tazzioli, Martina. (2015). Which Europe? Migrants' uneven geographies and counter-mapping at the limits of representation. (Online). Journal für kritische Migrations-und Grenzregimeforschung, 1 (2).(http://movements-journal.org/ issues/02.kaempfe/04.tazzioli--europemigrants-geographies-counter-mappingrepresentation.html, diakses $11 \mathrm{Mei}$ 2016)

Traub, James. (2016). If the refugees deal crumbles, there will be a hell to pay. (Online). (http:// foreign policy.com/2016/06/07/if-therefugee-deal-crumbles-there-will-be-hellto-pay-eu-turkey-germany-greece/, diakses 15 Juli 2016).

United Nations. Universal Declaration of Human Rights 1948. (Online). (http://www.un.org/ en/universal-declaration-human-rights/), diakses 24 April, 2016

UNHCR. (1992). Handbook on Procedures and Criteria for Determining Refugee Status under 
the 1951 Convention and the 1967 Protocol relating to the Status of Refugees.

\section{Artikel Berita Online}

Akel. (2016). NATO's involvement in the refugee issue a dangerous development. (https://www.akel. org.cy/en/2016/02/10/natos-involvementrefugee-issue-dangerous-development/ diakses 13 Juni 2016).

Al-Jazeera. (2015). Photos: Syrian refugees on the way to Europe. (Online). (http://www.aljazeera. com/indepth/features/2015/09/unpromisedland-greece-refugees-150924050229840.html, diakses 12 Mei 2016).

(2016). Germany registers record 1.1 million asylum seekers in 2015. (Online). (http:// america.aljazeera.com/articles/2016/1/6/ refugees-germany-more-than-1million. htmldiakses 15 Juli 2016).

BBC. (2015). Hungarian PM: Migrant crisis 'is a German problem'. (Online) (www.bbc.com/ news/world-europe-34136332, diakses 9 Juni 2016).

Council of Council. (2016). Slouching Toward Ankara: The EU-Turkey Migration Deal. (Online).

(http://www.cfr.org/councilofcouncils/global_ memos/p37825, diakses 30 April 2016).

Duetsche Welle. (2015). Hungary's Orban criticizes Merkel's 'moral imperialism'. (Online). (http:// www.dw.com/en/hungarys-orban-criticizesmerkels-moral-imperialism/a-18736240, diakses 12 Mei 2016).

EU Observer. (2015). Coalition of willing' announces EU-Turkey summit. (Online) (https:// euobserver.com/migration/131584, diakses 15 Juli 2016)

(2016). More refugees arriving in Italy than Greece. (Online). (https://euobserver. com/migration/133409, diakses 14 Juni 2016)

Global news. (2016). European Union strikes deal with Turkey to send back refugees. (Online). (http://globalnews.ca/ news/2586206/european-union-strikes-deal- with-turkey-to-send-back-refugees/), diakses 15 Mei 2016.

Independent. (2015). Refugee crisis: How Europe's alarming lack of unity over the

issue could bring about the break up of the EU. (Online). (http://www.independent.co.uk/ news/world/europe/refugee-crisis-howeuropes-alarming-lack-of-unity-over-theissue-could-bring-about-the-break-up-of10492151.html, diakses 12 Mei 2016)

New YorkTimes.(2016). E.U.Woos Turkeyfor Refugee Help, Ignoring Rights Crackdown. (Online). (http://www.nytimes.com/2016/03/09/world/ europe/turkey-european-union-refugees. html, diakses 20 Mei 2016).

Press TV. (2016). Merkel says EU-Turkey deal on refugee crisis will have setbacks. (Online). (http:// www.presstv.ir/Detail/2016/03/18/456446/ EU-Turkey-refugee-Finland-Juha-Sipila, diakses 20 Maret 2016).

Sputnik. (2016). EU Members Save Their Own Skin, Abandon Human Rights and European Values. (Online). (http://sputniknews.com/ europe/20150915/1027006776/eu-abandonsschengen-european-values-amid-refugeecrisis.html, diakses 13 Mei 2016).

The Guardian. (2015). Refugee crisis: Germany reinstates controls at Austrian border. (Online) (https://www.theguardian.com/world/2015/ sep/13/germany-to-close-borders-exitschengen-emergency-measures, diakses 16 Mei 2016).

(2016). Turkey and EU agree outline of 'one in, one out' deal over Syria refugee crisis. (Online). (http://www.theguardian.com/ world/2016/mar/08/european-leaders-agreeoutlines-of-refugee-deal-with-turkey, diakses 14 Mei 2016).

The Telegraph. (2016). Germany delivers further blow to EU's Schengen passport-free $z$ o n e. (Online). (http://www.telegraph.co.uk/news/ worldnews/europe/eu/12114174/Germanydelivers-further-blow-to-EUs-Schengenpassport-free-zone.html, diakses 24 April 2016). 